\title{
Out of Hours
}

\section{Electronic self check-in for patients:}

\author{
the costs and consequences
}

In some practices, a notice directs patients to check in for their booked appointments with their GP or nurse by using a computer screen instead of speaking to a receptionist. When I met this system for the first time its impersonality struck me as contrary to general practice's emphasis on personal and therapeutic relationships. So I asked six patients from other practices what they thought. They were resigned but critical.

\section{CRITICISMS, COMMENTS, AND COSTS}

Electronic self check-in is probably costeffective for the practice because it frees up receptionists to do other things. It is quick for patients: they need not wait their turn at the reception counter. But it has costs:

First, the system is symbolically and actually emotionally distant. The first contact between a person and an institution affects whether or not that person will feel secure lwe know that when welcoming guests). The computer screen stands at the boundary between the outside world and the practice, where once the receptionist stood. Replacing a live person with a machine at this crucial boundary can raise apprehension about what lies inside that boundary. Second, the system's impersonality jettisons the potential therapeutic value of the encounter between the patient and the receptionist. The exchange of greetings, and perhaps a moment of ordinary friendly chat between the two, can lessen patients' anxiety by reassuring them that their own and other patients' lives can carry on normally, in spite of the uncertainties of their clinical situations.

Lifting patients' anxiety is comforting for those patients who experience it, and probably helps them manage their part in the GP-patient consultation better. This should also help their GP. Third, the system jeopardises less obvious benefits. A positive patient-receptionist encounter can foster a sense of connection between patient and practice. People's feelings of connection to the people and to the social institutions to which they belong form part of a framework of goodwill and security through which people can most fully realise their autonomy. ${ }^{1}$ Patients' ability to articulate their goals is integral to decisions about what course of action is right for them. ${ }^{2}$ The practice can benefit, too - patients have a stake in seeing it sustained as a beneficent and reliable part of the community.

Some patients will disregard (in NHS speak 'fail to comply with') directions to use the electronic check-in screen or they will have appointments to make or questions to ask. So personal contact is not completely bypassed. But devaluing and reducing receptionists contacts with patients may tend to make them view patients as interruptions to be tolerated rather than as people to be cared about and respected. One patient remarked that receptionists no longer looked up as patients approached the reception counter. In another practice with self check-in, the receptionists drank mugs of tea in full view of patients in the waiting area, as if they did not exist or matter. By contrast, in a practice without self check-in, the receptionists had put sprigs of Michaelmas daisies in a small vase on the counter, giving pleasure to patients, healthcare professionals, and themselves. These are but few observations. But they epitomise the kinds of details through which life is lived and witnessed, details that contribute to feelings of ease or unease, confidence or distrust.

In addition, the design of the model of electronic self check-in screen commonly used is bizarrely unfortunate. Patients are instructed to press the screen to select successively their sex, and their day, month, and year of birth (those ill or unfamiliar with written English could find this difficult).

This is in effect a stripping process, a modern version of the stripping of hospital patients of their identity by removing their clothes and possessions, which led to protest in the 1960s. ${ }^{3}$ Electronic stripping takes away from patients their name with all that that means to them; it then reconstructs their identity by collecting together adventitious differences between them and every other patient in the practice. At the end of the process, it throws their name back to them and tells them with whom they have their appointment, things they already knew. A better system to threaten patients sense of their own autonomy, agency, and connection to other people could scarcely be devised. 'Abominable' was the word used by one patient. Another pointed out that the system is unhygienic: everyone's fingers touch the screen.

\section{DISCUSSION}

GPs must manage their practices effectively but the methods used should be compatible with the objectives and ethos of general practice. Some of the features of electronic self check-in match a process called

\section{ADDRESS FOR CORRESPONDENCE}

Charlotte Williamson

Midgley House, Spring Lane, Heslington, York Y010 5DX, UK.

\section{E-mail: charlottedwmsn.freeserve.co.uk}

managerial-industrialisation ${ }^{4}-$ where values, ideas, and technologies are borrowed from industry: staff are replaced by machines: people are treated impersonally; relationships between people are devalued; procedures are standardised and speeded up; efficiency and cost-effectiveness are promoted over other social or moral values; work is pushed down to the lowest level and status of operator possible - here the patient. 4.5

Such tenets and methods need to be scrutinised for their underlying purposes and for their political implications for the medical profession and for patients. ${ }^{6}$ Thinking politically and strategically about health care - those whose interests are supported and those who are undermined by the government's managerial proposals and demands - can be difficult for doctors, as it is for the rest of us. But we must. Otherwise, small steps that may seem unimportant, even beneficial, can inadvertently set the course of general practice in directions that as patients or as GPs we may not want or may not believe to be morally right.

\section{Charlotte Williamson,}

Chair, Patients Liaison Group 1994-1997, Royal College of General Practitioners, London.

\section{DOI: 10.3399/bjgp16X684025}

\section{REFERENCES}

Hancock E. The girl within. New York, NY: Ballantine Books, 1989.

2. Lehman R, Tejani AM, McCormack J, et al. Ten Commandments for patient-centred treatment. Br J Gen Pract 2015; DOI: 10.3399/ bjgp $15 \times 687001$.

3. Cohen GL. What's wrong with hospitals? Harmondsworth: Penguin Books, 1964.

4. Iliffe S. From general practice to primary care: the industrialization of family medicine. Oxford: Oxford University Press, 2008.

5. Williamson C. Alford's theoretical political framework and its application to interests in health care now. Br J Gen Pract 2008; DOI: 10.3399/bjgp08X319558.

6. Alford RR. Health care politics. ideological and interest group barriers to reform. Chicago: University of Chicago Press, 1975. 